\title{
Protective effects of BMSCs in combination with erythropoietin in bronchopulmonary dysplasia-induced lung injury
}

\author{
ZHAO-HUA ZHANG ${ }^{1}$, YAN-YAN PAN ${ }^{2}$, RUI-SHENG JING ${ }^{3}$, YUN LUAN $^{4}$, LUAN ZHANG $^{1}$, \\ CHAO SUN ${ }^{4}$, FENG KONG ${ }^{4}, \mathrm{KAI}^{-\mathrm{LIN} \mathrm{LI}^{4}}$ and YI-BIAO WANG ${ }^{1}$ \\ ${ }^{1}$ Department of Pediatrics, The Second Hospital of Shandong University, Jinan, Shandong 250033; \\ ${ }^{2}$ Department of Pediatrics, Qilu Children's Hospital of Shandong University, Jinan, Shandong 066600; \\ ${ }^{3}$ Department of Internal Medicine, Xinji Central Hospital, Changli, Hebei 250000; \\ ${ }^{4}$ Central Research Laboratory, The Second Hospital of Shandong University, \\ Jinan, Shandong 250033, P.R. China
}

Received July 20, 2015; Accepted May 12, 2016

DOI: $10.3892 / \mathrm{mmr} .2016 .5378$

\begin{abstract}
Bronchopulmonary dysplasia (BPD) is the most common type of chronic lung disease in infancy, for which no effective therapy is currently available. The aim of the present study was to investigate the effect of treatment with bone marrow mesenchymal stem cells (BMSCs) in combination with recombinant human erythropoietin (rHuEPO) on BPD-induced mouse lung injury, and discuss the underlying mechanism. The BPD model was established by the exposure of neonatal mice to continuous high oxygen exposure for 14 days, following which $1 \times 10^{6} \mathrm{BMSCs}$ and 5,000 U/kg rHuEPO were injected into the mice $1 \mathrm{~h}$ prior to and 7 days following exposure to hyperoxia. The animals received four treatments in total ( $\mathrm{n}=10$ in each group). After 14 days, the body weights, airway structure, and levels of matrix metalloproteinase-9 (MMP-9) and vascular endothelial growth factor (VEGF) were detected using histological and immunohistochemical analyses. The effect on cell differentiation was observed by examining the presence of platelet endothelial cell adhesion molecule (PECAM) and VEGF using immunofluorescence. Compared with the administration of BMSCs alone, the body weight, airway structure, and the levels of MMP-9 and VEGF were significantly improved in the BMSCs/rHuEPO group. The results of the present study demonstrated that the intravenous injection of BMSCs significantly improved lung damage
\end{abstract}

Correspondence to: Professor Yi-Biao Wang, Department of Pediatrics, The Second Hospital of Shandong University, 247 Beiyuan Dajie, Jinan, Shandong 250033, P.R. China

E-mail:wangyibiao@sdu.edu.cn

Professor Yun Luan, Central Research Laboratory, The Second Hospital of Shandong University, 247 Beiyuan Dajie, Jinan, Shandong 250033, P.R. China

E-mail: y_luan@163.com

Key words: bone marrow mesenchymal stem cells, recombinant human erythropoietin, bronchopulmonary dysplasia in the hyperoxia-exposed neonatal mouse model. Furthermore, the injection of BMSCs in combination with intraperitoneal injection of rHuEPO had a more marked effect, compared with BMSCs alone, and the mechanism may be mediated by the promoting effects of BMSCs and EPO. The results of the present study provided information, which may assist in future clinical trials.

\section{Introduction}

Bronchopulmonary dysplasia (BDP) is a disease affecting neonatals, particularly premature neonatals in which the structural development of the alveoli is blunted as a consequence of inflammation and oxygen toxicity (1). The disease is complex and is characterized by disturbed alveologenesis (2). The pathogenesis depends on the interaction of a susceptible host with a multitude of environmental risk factors, including growth factors, cytokines, other substances that may act as ligands, receptors, signaling molecules and transcription factors, and the protein products of cell activity, including enzymes involved in matrix reconstruction, retinoids and elastin $(3,4)$.

Hyperoxia-induced lung injury is a model of lung disease similar to BPD, with rarification and simplification of alveoli, thickened septa and vascular damage $(5,6)$. Cell therapy is a potential therapeutic approach for lung disorders, including BDP. Previous advances have shown that mesenchymal stromal cells (MSCs) can protect the lung in the repair of injured lung tissues in several animal models, including endotoxin, bleomycin, monocrotaline and hypoxia-induced lung injury (7-9). Studies have also shown that the intravenous or intratracheal administration of MSCs can protect against hyperoxic lung injury through reducing inflammation and improving alveolar structure $(10,11)$. However, MSC engraftment in this disease is low, and therapeutic benefit is likely to be triggered by a paracrine-mediated mechanism, immunomodulation (12) or other mechanisms, which remain to be elucidated.

The vascular endothelial growth factor (VEGF) pathway and nuclear factor- $\kappa \mathrm{B}(\mathrm{NF}-\kappa \mathrm{B})$, a transcription factor traditionally associated with inflammation, are essential for 
alveolarization in the neonatal lung (13). The overexpression of transforming growth factor $\beta$ (TGF- $\beta$ ), a stimulus for myofibroblastic differentiation, in neonatal mouse lungs results in structural changes of BPD, including abnormal alveolar structure and vascular development (14). Erythropoietin (EPO) is a glycoprotein hormone produced primarily by the adult kidney, which regulates the production of red blood cells, exerting its hematopoietic effects by stimulating the proliferation of committed erythroid progenitor cells (15). In the last decade, it has emerged that EPO is an important cytoprotective cytokine against various stress-inducing events in several organs $(16,17)$. The beneficial effects of EPO in pulmonary diseases have also been reported (18). Ozer et al (19) reported that treatment with recombinant human erythropoietin (rhEPO) during hyperoxia exposure is associated with improved alveolar structure, enhanced vascularity and decreased fibrosis, therefore, treatment of preterm infants with EPO may reduce the risk of developing BPD. Shang et al (20) reported that ERO attenuates pulmonary inflammation and suppresses the levels of tumor necrosis factor- $\alpha(\mathrm{TNF}-\alpha)$ and interleukin-1 $\beta$ (IL-1 $\beta$ ) overproduced during acute endotoxemia, which is partially mediated by the inhibition of NF- $\kappa \mathrm{B}(20)$. Although treatment with rhEPO is associated with improved alveolar structure, enhanced vascularity and decreased fibrosis, these effects require cautious interpretation due to the limited number of animals included, and further investigation is required.

Previous studies have investigated the potential therapeutic effect of stem cells in hyperoxic lung injury in neonatal rats, and of MSCs, which are able to prevent arrested alveolar and vascular growth, partly via paracrine activity $(11,21)$. These may offer novel therapeutic strategies for treatment of lung disease; however, their potential roles in neonatal lung injury have not been identified. In the present study, the different effects of MSCs, EPO alone or MSCs + EPO in the treatment of BPD were investigated as promising therapeutic targets for the treatment of BPD.

\section{Materials and methods}

Animals. Neonatal C57BL/6 mice (age, 24 h; weight, $12 \mathrm{~g}$ ) were used in all experiments in the present study. The C57BL/6-green fluorescent protein (GFP) mice were purchased from the Animal Resource Center of the Fourth Military Medical University (Xi'an, China) and maintained in a temperature controlled environment $\left(22-24^{\circ} \mathrm{C}\right)$ under a 12-h light/dark cycle with access to food and water ad libitum. The mice were randomized into various groups and weighed, and blood samples were collected. All animal procedures were approved by the animal ethics committee of Shandong University (Jinan, China) and were performed in accordance with the Guide for the Care and Use of Laboratory Animals, published by the US National Institutes of Health (NIH Publication no. 85-23, revised 1996).

Cell isolation and culture. BMSCs were isolated from the bone marrow from the tibia and femurs of all four limbs of 6-8-week-old C57BL/6-GFP transgenic mice using a previously reported approach (22). Briefly, fresh BMSCs were isolated by flushing Dulbecco's modified Eagle's medium (DMEM; American Type Culture Collection, Manassas, MD,
USA) containing $1 \%$ penicillin-streptomycin (Sigma-Aldrich, St. Louis, MO, USA) through the medullary cavity of the mouse femurs. The cells were isolated using a Ficoll density gradient centrifugation method (1.077; Sigma-Aldrich) at $800 \mathrm{x} \mathrm{g}$ for $20 \mathrm{~min}$ at room temperature. The isolated BMSCs were cultured $\left(1 \times 10^{6}\right.$ cells per $100-\mathrm{mm}$ cell culture dish (Corning Incorporated, Corning, NY, USA) and expanded in low glucose culture containing culture medium (GE Healthcare Life Sciences, Logan, UT, USA) containing 10\% fetal calf serum (Becton Dickinson; BD Biosciences, San Diego, CA, USA) at $37^{\circ} \mathrm{C}$ in $5 \% \mathrm{CO}_{2}$. After $48 \mathrm{~h}$, the nonadherent cells were removed, fresh medium was added, and the culture was maintained for 7 days. The cells were then washed three times with Tris-buffered saline, which was followed by a 1-h incubation in the dark with fluorescein isothiocyanate, (FITC)-conjugated goat anti-rabbit $\operatorname{IgG}(\mathrm{H}+\mathrm{L})$ secondary antibody (cat. no. ZF-0311; dilution, 1:200, ZSGB-Bio Co., Beijing, China) in phosphate-buffered saline (PBS). 4,6-Diamino-2-phenyl indole (DAPI) was used for nuclear counterstaining. Images of the cells were captured using a camera system connected to a fluorescence microscope (ECLIPSE 90i and NIS-Elements AR system, Nikon Corporation, Tokyo, Japan). The cells had characteristic immunoreactivities for cell markers CD44, CD117, CD34 and CD106 (Santa Cruz Biotechnology, Inc., CA, USA) on the basis of immunocytochemistry. Briefly, $1 \times 10^{4}$ cells grown on a poly-1-lysine-coated 24 -well plate were washed three times with PBS and fixed in $4 \%$ paraformaldehyde for $30 \mathrm{~min}$ at room temperature, following which the cells were permeabilized with $0.1 \%$ Triton X-100/PBS for $20 \mathrm{~min}$ and blocked with $4 \%$ goat serum for $1 \mathrm{~h}$. The cells were then incubated with rat monoclonal CD44 (1:100; cat. no. sc-18849; Santa Cruz Biotechnology, Inc.), CD106 (1:100; cat. no. ab24853; Abcam,Cambridge, MA, USA) and CD117 (1:100; cat. no. ab24870; Abcam) antibodies, and a goat polyclonal CD34 (1:100; cat. no. sc-7045, Santa Cruz Biotechnology, Inc.) antibody for $1 \mathrm{~h}$ at room temperature in the dark (23).

BMSCs were suspended with trypsin and $5 \times 10^{5}$ cells, washed twice with PBS containing $0.5 \%$ bovine serum albumin (Sigma-Aldrich), were incubated with 1:200 dilutions of fluorochrome-conjugated specific or isotype control antibodies for $30 \mathrm{~min}$ at $4^{\circ} \mathrm{C}$. The BMSCs were subsequently resuspended in PBS and incubated with specific or isotype control antibodies: Phycoerythrin (PE)/Cy5-conjugated antiCD44 (cat. no. ab25579), FITC-conjugated anti-CD106 (cat. no. ab24853), PE-conjugated anti-CD34 (cat. no. ab23830), and FITC-conjugated anti-CD117 (cat. no. ab24870; all Abcam) resuspended in PBS and incubated with mouse anti-human monoclonal antibodies for $30 \mathrm{~min}$ at $4^{\circ} \mathrm{C}$. After being washed, the cells were resuspended in PBS for fluorescence-activated cell sorting (FACS) analysis.

Preparation of hyperoxia-induced lung injury and experimental groups. The neonatal C57BL/6 mice were randomly divided into the following four groups ( $\mathrm{n}=10$ in each group): Control, high oxygen, BMSCs alone and BMSCs/rHuEPO. Hyperoxia exposure of the neonatal mice was prepared, as previously reported (24). Briefly, the BPD group of neonatal C57BL/6 mice (age, $24 \mathrm{~h}$ ) were placed in chambers in which the oxygen concentration was maintained at $\mathrm{FiO}_{2}=0.60$. 

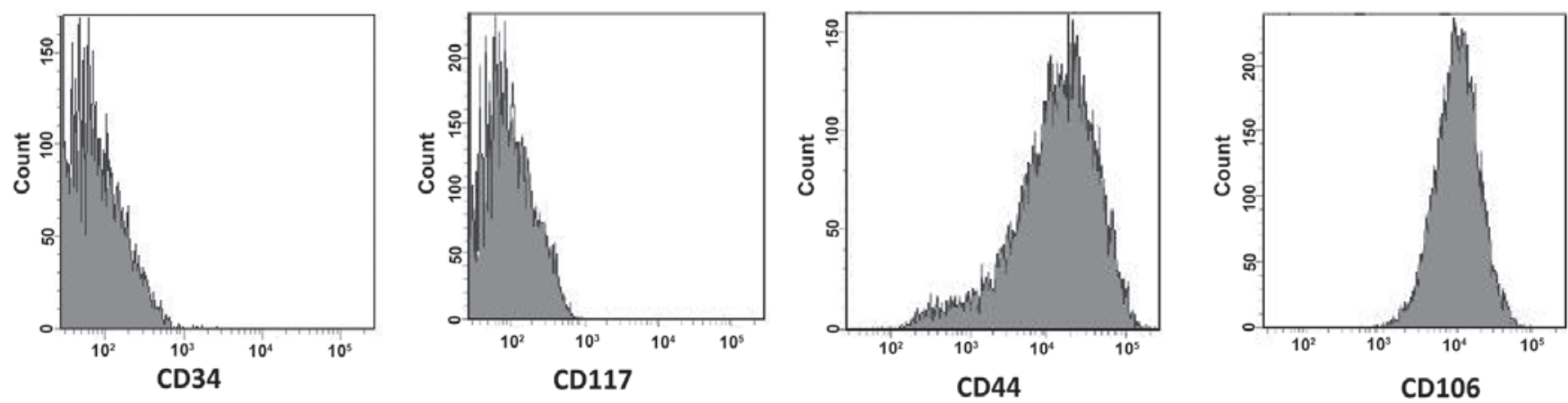

Figure 1. Characterization of cultured bone mesenchymal stem cells. The surface markers were determined by fluorescence activated cell sorting.

The exposure to hyperoxia was continuous, and the animals were exposed to the hypoxic environment for 14 days, with a brief interruption for animal care ( $<10 \mathrm{~min} /$ day) Subsequently, $1 \times 10^{6}$ BMSCs were administered intravenously and $5,000 \mathrm{U} / \mathrm{kg}$ rHuEPO was administered by intraperitoneal injection, $1 \mathrm{~h}$ prior to and 7 days following hyperoxia exposure of the neonatal mice.

Lung histology and morphometric analysis. The lung tissues were prepared for histological examination, as previously described (24). Briefly, the mice were sacrificed by intraperitoneal injections of pentobarbital $(100 \mathrm{mg} / \mathrm{kg})$ at 14 days old. Following sacrifice, the lungs were fixed with $4 \%$ paraformaldehyde solution overnight, and the left lower lobe was embedded in paraffin. Tissue sections were produced using a microtome set at 4-5 $\mu \mathrm{m}$ (Leica RM226; Leica Microsystems $\mathrm{GmbH}$, Heidelberg Germany). Alveolarization was assessed by performing radial alveolar counts (RACs), according to standard methods, as previously described (25). Briefly, from the center of the respiratory bronchiole, a perpendicular line was drawn to the edge of the acinus, as defined by a connective tissue septum or the pleura, and the number of septa intersected by this line were counted. A total of five counts were performed for each animal, and the average count from the five high-power fields was randomly selected. These experiments were performed by two examiners blinded to treatment assignment.

Immunohistochemical staining. On day 14, the mice were sacrificed by intracoronary perfusion of $10 \% \mathrm{KCl}$ solution, and the lungs were removed and fixed in $4 \%$ paraformaldehyde/PBS for $24 \mathrm{~h}$, followed by storage in $70 \%$ ethanol. The left lower lobe was embedded in paraffin, sectioned into 4-5 $\mu$ m-thick sections, deparaffinized in xylene, and rehydrated by serial immersions in 100, 95, 85 and $75 \%$ ethanol, and $100 \%$ water. Following blocking with $4 \%$ normal goat serum in PBS, the slides were incubated with primary antibodies overnight at $4^{\circ} \mathrm{C}$, and biotinylated HRP-conjugated rabbit $\operatorname{IgG}(\mathrm{H}+\mathrm{L})$ polyclonal secondary antibody (1:200; cat. no. ZB-2306; ZSGB-Bio Co.) for $20 \mathrm{~min}$ at room temperature. The following primary antibodies were used: Rabbit polyclonal MMP-9 (1:200; cat. no. ab3889; Abcam) and VEGF (1:200; cat. no. ab46154; Abcam), which was followed by a 1 -h incubation in the dark with tetrametrylrhodarnine isothiocyante-conjugated goat anti-rabbit $\mathrm{IgG}(\mathrm{H}+\mathrm{L})$ secondary antibody (cat. no. ZF-0316; dilution, 1:200; ZSGB-Bio Co., Ltd). A total of 10 serial cortex and hippocampal sections (50 $\mu \mathrm{m}$ interval for each section) from each animal ( $\mathrm{n}=10$ for each group) were used to quantify each parameter. The staining was analyzed using the image-analyzing system, Image Pro Plus 6 (Media Cybernetics, Rockville, MD, USA), as previously described (26).

Statistical analysis. All data are expressed as the mean \pm standard error of the mean. Comparisons of parameters between two groups were made using an unpaired Student's $t$-test. Comparisons of parameters among three groups were made using one-way analysis of variance, followed by Scheffe's multiple comparison test. Statistical analysis performed using the SPSS 13.0 software (SPSS, Inc., Chicago, IL, USA). P<0.05 was considered to indicate a statistically significant difference.

\section{Results}

FACS. The surface markers of BMSCs were determined using FACS and showed that the BMSCs were positive for CD44 (93.14\%) and CD106 (95.37\%), but negative for CD34 (1.69\%) and CD117 (2.58\%; Fig. 1).

Body weights. A total of 10 animals were represented in each treatment group and at each time point. The body weights of the animals were lower in the BPD group (positive control) when the mice were 7- $(5.89 \pm 0.26 \mathrm{~g})$ and $14-(7.95 \pm 0.22 \mathrm{~g})$ days-old, compared with the mice exposed to room air $(8.34 \pm 0.25$ and $11.05 \pm 0.28$, respectively, $\mathrm{P}<0.05)$. The body weights in the $\mathrm{BMSC}$ alone and $\mathrm{BMSC} / \mathrm{rHuEPO}$ treatment groups were higher at 7 days old $(6.84 \pm 0.20$ and $7.42 \pm 0.23 \mathrm{~g}$, respectively) and 14 days old $(9.27 \pm 0.21$ and $10.38 \pm 0.26 \mathrm{~g}$, respectively), compared with the hyperoxia group $(\mathrm{P}<0.05)$. Weight preservation was most marked in the BMSCs/rHuEPO-treated mice ( $\mathrm{P}<0.05$; Fig. 2).

Lung histology and morphometric analyses. To investigate whether treatment with BMSCs and BMSCs/rHuEPO have beneficial effects on hyperoxia exposure-induced impairment in lung structure, morphometric analysis was performed using RACs. Compared with the room air control, RACs were lower in the 14-day-old C57BL/6 mice exposed to hyperoxia, but higher in the mice treated with BMSCs alone and with BMSCs/rHuEPO during hyperoxia on postnatal days 7 and 14, compared with those of the BPD group. In addition, improved 


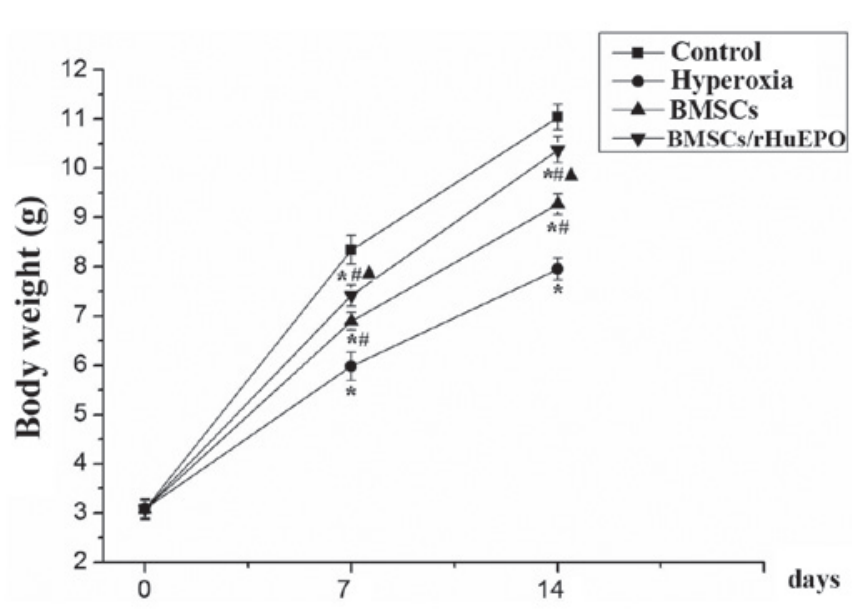

Figure 2. Effect of BMSCs and BMSCs/rHuEPO on body weight. Body weights were lower in the hyperoxia group at 7 and 14 days, compared with the control. The BMSCs- and BMSCs/rHuEPO-injected groups showed higher body weights at 7 and 14 days old, compared with the hyperoxia group. Weight preservation was improved in the BMSCs/rHuEPO group, compared with the BMSCs group. The data are presented as the mean \pm standard error of the mean $(\mathrm{n}=10) .{ }^{*} \mathrm{P}<0.05$, compared with the control group; ${ }^{\text {"}} \mathrm{P}<0.05$, compared with the hyperoxia group; ${ }^{\mathbf{A}} \mathrm{P}<0.05$, compared with the BMSCs group. BMSCs, bone marrow mesenchymal stem cells; rHuEPO, recombinant human erythropoietin.

weight preservation was shown in the BMSCs/rHuEPO-treated mice, compared with the mice treated with BMSCs alone (Fig. 3).

Protein expression levels of MMP-9 and VEGF in lung tissues. The results of the immunohistochemical staining analysis revealed that exposure of the neonatal mice to hyperoxia for 14 days resulted in significant increases in the protein expression levels of MMP-9 in the lungs, and a decrease in VEGF. The alterations in these proteins were significantly improved following treatment with BMSCs alone and with BMSCs/rHuEPO on day 14. Of note, the improvement in these protein expression levels were more marked in the BMSCs/rHuEPO group, compared with the BMSCs only group (Fig. 4).

Identification of the injected BMSCs. On day 14 following the injection of BMSCs from the C57BL/6-GFP mice,cytochemical staining of vessel markers, PECAM (red) and VEGF (red), in the lung tissues were observed. Images were captured using a camera system connected to a fluorescence microscope (Fig. 5). However, the differentiation did not differ between the BMSCs alone and BMSCs/rHuEPO groups.

\section{Discussion}

There has been substantial interest in the potential therapeutic effect of stem cells as a novel approach to a diverse range of lung diseases, including hyperoxic injury in neonatal rats $(21,27)$. The intravenous or intra-alveolar administration of BMSCs attenuates the severity of lung damage in adult rats following bleomycin- and endotoxin-induced lung injury $(5,8)$. Potential mechanisms for BMSC therapy-induced improvements in lung structure include engraftment, anti-inflammatory or immunomodulatory functions, and anti-apoptotic effects. Previous
A Control

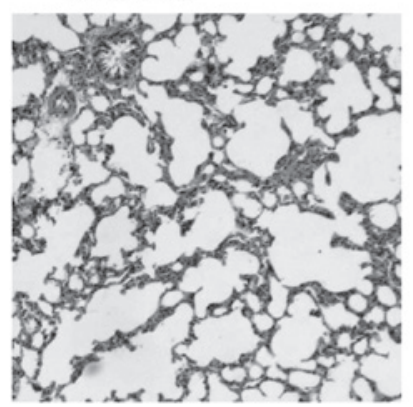

BMSCs

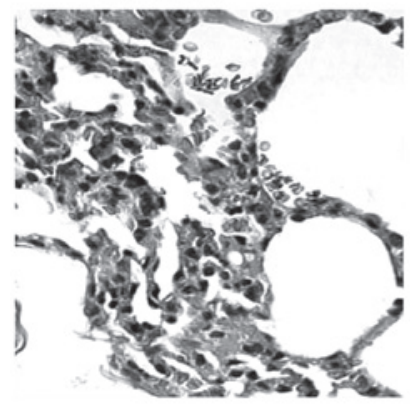

BPD

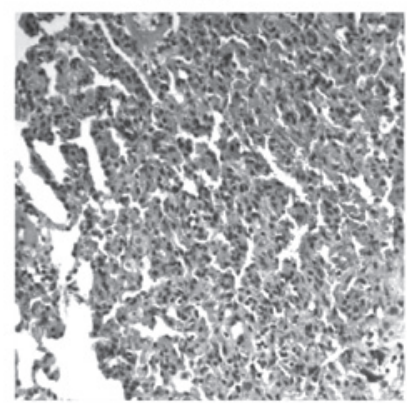

BMSCs/rhuEPO

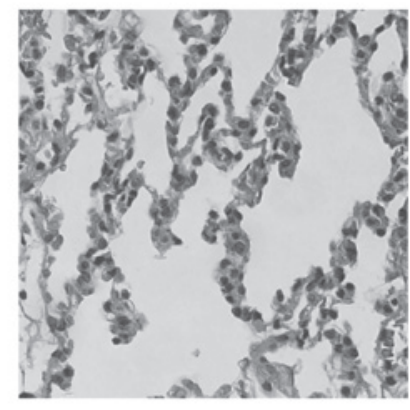

B

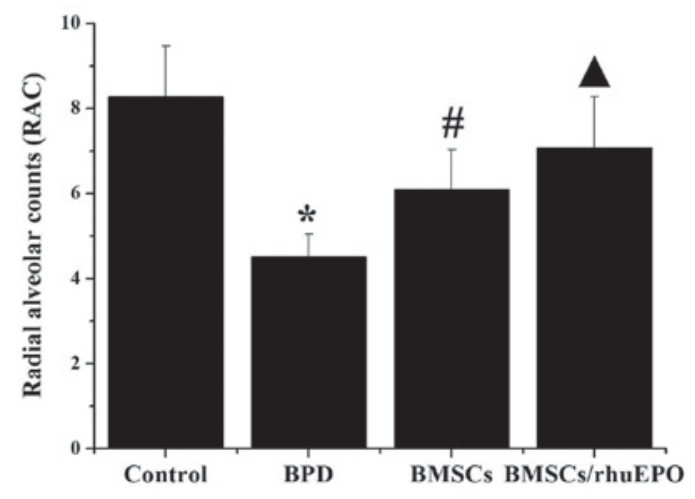

Figure 3. Hyperoxia impairs lung structure in neonatal mice. (A) Effects of treatment with BMSCs or BMSCs/EPO during hyperoxia for 14 days on lung histology (magnification x200). (B) Effects of treatment with BMSCs or BMSCs/rHuEPO during hyperoxia on RACs. Treatment with BMSCs and BMSCs/EPO during hyperoxia increased RACs. Data are presented as the mean \pm standard error of the mean $(n=10)$. ${ }^{*} \mathrm{P}<0.05$, compared with the control group; ${ }^{\#} \mathrm{P}<0.05$, compared with the BPD group; ${ }^{\mathbf{A}} \mathrm{P}<0.05$, compared with the BMSCs group. BMSCs, bone marrow mesenchymal stem cells; rHuEPO, recombinant human erythropoietin; BPD, bronchopulmonary dysplasia; RACs, radial alveolar counts.

studies have indicated that BMSCs can prevent arrested alveolar and vascular growth, in part, through paracrine activity in an experimental model of neonatal lung injury in rats $(11,28)$. These reports may offer novel therapeutic strategies for lung diseases, which currently lack efficient treatments. However, several issues require further investigation (29) and the potential role of BMSCs in the setting of neonatal lung injury remain to be fully elucidated (30). BMSCs can migrate to, or be involved in the development of lung tissue (31-34), and several studies have demonstrated that stem/progenitor cells have the potential for use as cellular therapies to contribute to lung repair mechanisms following acute lung injury $(34,35)$. The present study demonstrated that the intravenous injection of BMSCs significantly improved body weight and airway 
A

\section{Control}

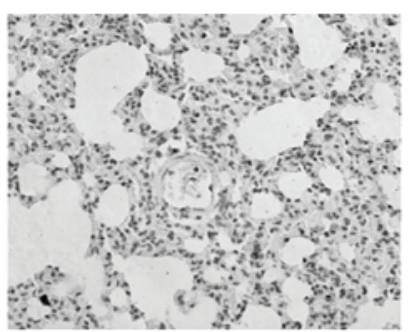

B

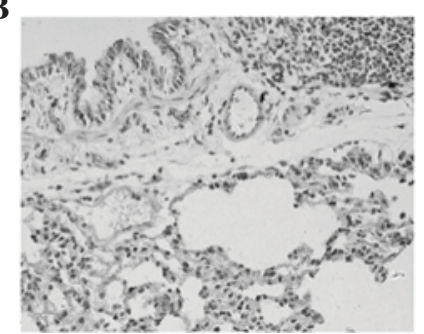

C
BPD
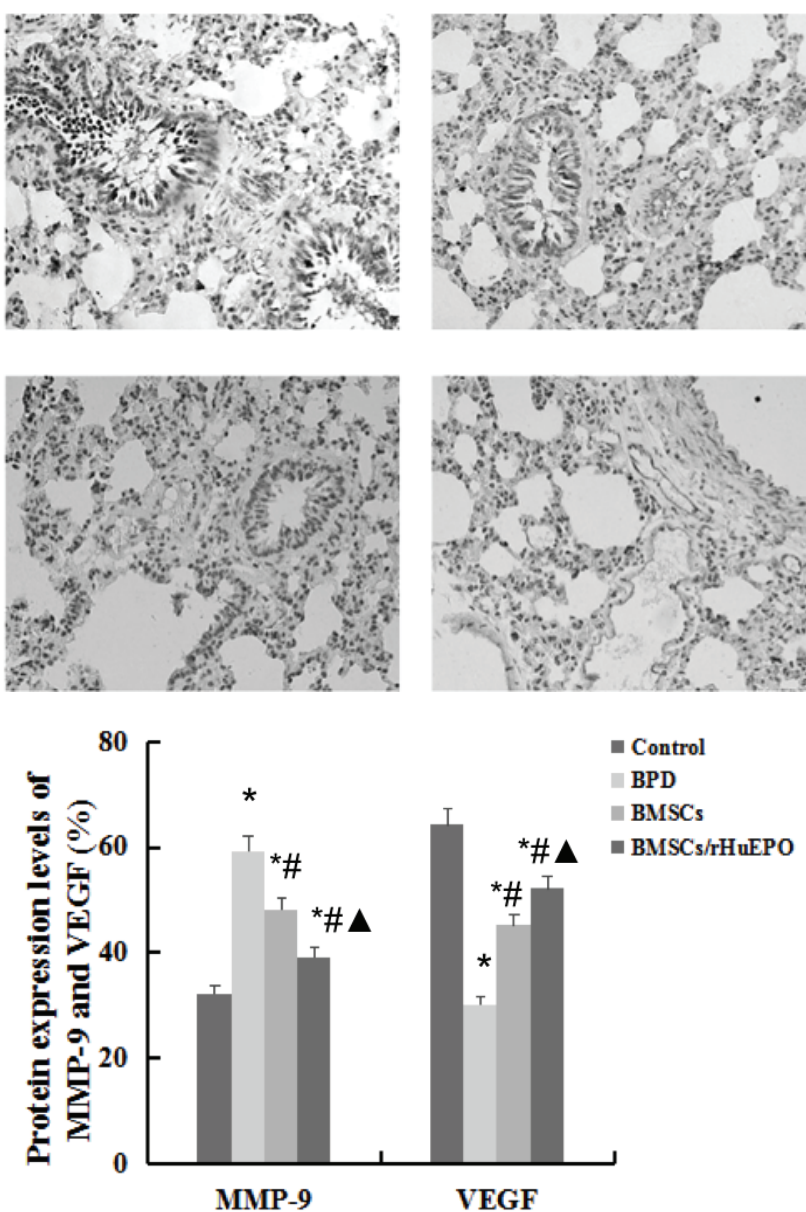

BMSCs/rhuEPO
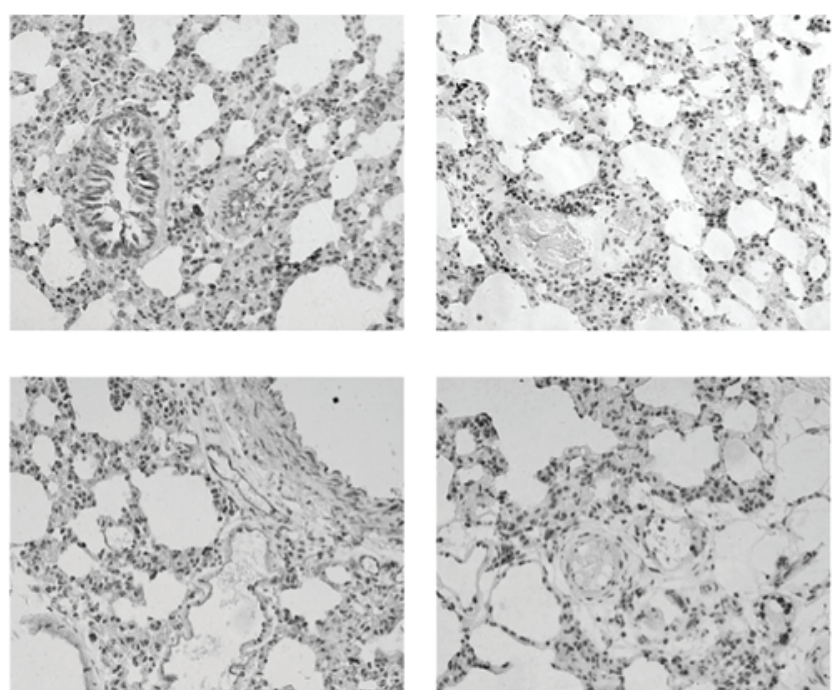

Figure 4. Examination of (A) MMP-9 and (B) VEGF protein expression levels in the lung tissues (magnification, x200). (C) Quantitative results of protein expression. Data are presented as the mean \pm standard error of the mean $(n=10)$. ${ }^{*} \mathrm{P}<0.05$ vs. control; ${ }^{\#} \mathrm{P}<0.05$ vs. BPD group; ${ }^{\wedge} \mathrm{P}<0.05$ vs. BMSCs group. MMP, matrix metalloproteinase; VEGF, vascular endothelial growth factor; BMSCs, bone marrow mesenchymal stem cells; rHuEPO, recombinant human erythropoietin; BPD, bronchopulmonary dysplasia.
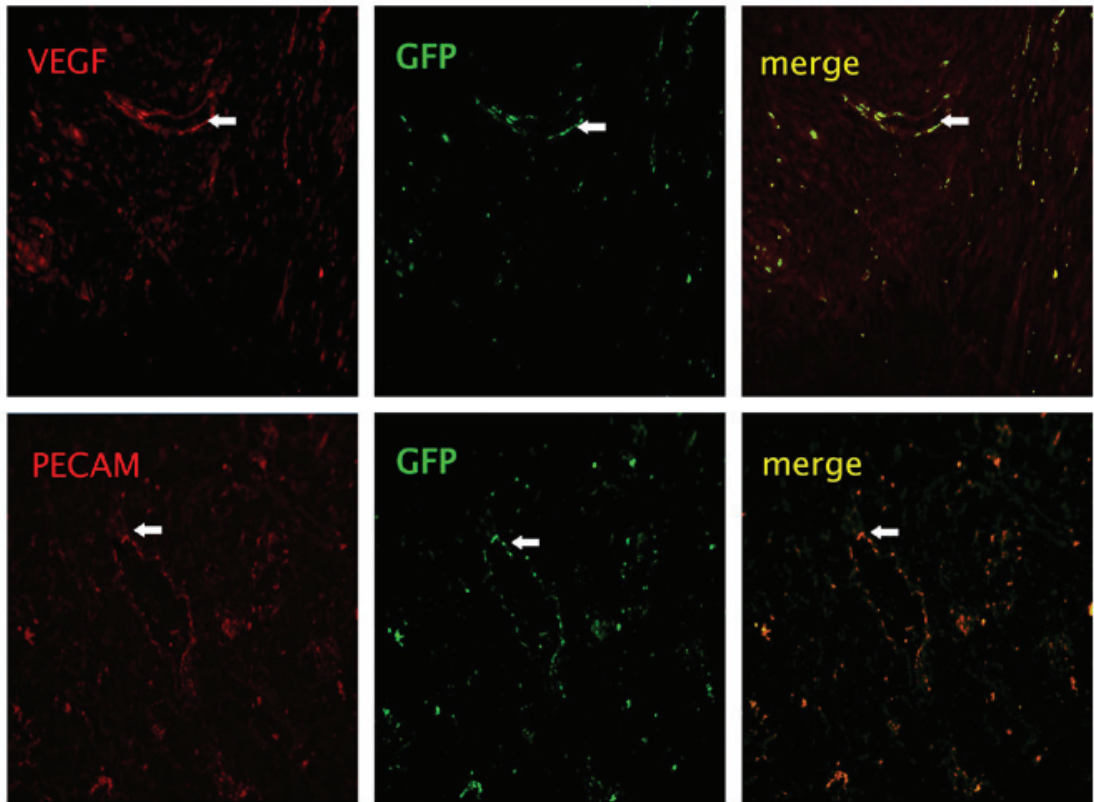

Figure 5. Double-labeled cells were observed using a fluorescence microscope. At 14 days of age, the injected cells from the C57BL/6-GFP mice underwent proliferation, as shown by C57BL/6-GFP cells (green), vessels markers PECAM and VEGF (red), and the merged images (yellow color), indicated by white arrows. (Magnification x200). GFP, green fluorescent protein; VEGF, vascular endothelial growth factr; PECAM, platelet endothelial cell adhesion molecule. 
structure following lung injury in hyperoxia-exposed neonatal mice, Of note, the injection of BMSCs in combination with rHuEPO showed more marked improvement, compared with injection of the BMSCs alone.

MMPs are a family of proteolytic enzymes that degrade various components of the ECM, and members of MMPs family include MMP-1, MMP-2, MMP-8 and MMP-9 (36). MMP-9 has been shown to be a key proteinase, promoting the destruction of matrix and basement membranes (37). Studies have shown that the concentrations of MMP-9 are elevated in the tracheal aspirates of neonates with $\operatorname{BPD}(38,39)$. The findings of the present study may support the suggestion that MMP-9 and TGF- $\beta$ are important in neonatal lung injury and BPD. Treatment with rhEPO during hyperoxia exposure is associated with improved alveolar structure, enhanced vascularity and decreased fibrosis in BPD (19). In addition, EPO can attenuate pulmonary inflammation and suppress the overproduction of TNF- $\alpha$ and IL-1 $\beta$ induced by acute endotoxemia (20). In the present study, the results showed that the protein expression levels of MMP-9 were significantly lower following treatment with BMSCs alone and in combination with rHuEPO following exposure of the neonatal mice to hyperoxia for 14 days. However, the expression of MMP-9 was lower in the BMSCs/rHuEPO group, compared with the BMSCs only group. These results showed that treatment with BMSCs or BMSCs/rHuEPO reduced lung injury, and that EPO promoted the effect of the BMSCs through paracrine or anti-inflammatory mechanisms.

VEGF is recognized as being essential in the regulation of pulmonary vascular growth and development, stimulating angiogenesis and endothelial survival (40). In BDP animal models and in the lungs of premature infants who succumbed to BPD-associated mortality, the expression levels of VEGF are decreased (41-43). Inhibiting VEGF receptor 2 (VEGFR2) causes rarefaction of pulmonary vessels and impairs alveolar formation (41) in neonatal rats, whereas the enhancement of VEGF signaling rescues the alveolar disruption induced by hyperemia (44). By contrast, inhibiting postnatal angiogenesis impairs alveolarization (27), and decreased pulmonary capillary density is observed in animal models and patients who have succumbed to BPD-associated mortality (45). At present, although the association between pulmonary angiogenesis and lung development is clear, the transcription mediation of pulmonary angiogenesis remains to be elucidated. As reported, $\mathrm{NF}-\kappa \mathrm{B}$ directly regulates the expression of the proangiogenic molecule, VEGFR2, in the developing pulmonary vasculature (13). The findings of the present study showed that the protein expression levels of VEGF were significantly improved 14 days following treatment with BMSCs alone or with BMSCs/rHuEPO during exposure of the neonatal mice to hyperoxia. These results supported the hypothesis that VEGF is involved in neonatal lung injury. Of note, the present study found that EPO further promoted this effect.

In conclusion, supplemental oxygen is required for the survival of premature infants, however, this may lead to the accumulation of reactive oxygen species, impairment of alveolarization and dysmorphic pulmonary vasculature. The present study demonstrated that intravenous injection of BMSCs significantly improved the damaged airway structure, and rescued the levels of MMP-9 and VEGF in hyperoxia-exposed neonatal mouse lungs. It was found that treatment with BMSCs in combination with intraperitoneal injection of rHuEPO further enhanced these improvements, compared with BMSCs alone.

Taken together, the data obtained in the present study suggested that BMSCs from C57BL/6-GFP mice provided a novel approach for the treatment of BPD in an in vivo model of lung injury. The results also indicated that the combination of BMSCs and EPO had more marked effects, compared with BMSCs alone 14 days following injection. These findings suggested the potential to rescue BPD damage by the injection of BMSCs alone or BMSCs/EPO in mice, providing valuable information for future clinical trials.

\section{Acknowledgements}

This study was supported by a grant from the Seed Foundation of the Second Hospital of Shandong University (grant no. S2013010001).

\section{References}

1. Madurga A, Miziková I, Ruiz-Camp J and Morty RE: Recent advances in late lung development and the pathogenesis of bronchopulmonary dysplasia. Am J Physiol Lung Cell Mol Physiol 305: L893-L905, 2013.

2. Pietrzyk JJ, Kwinta P, Wollen EJ, Bik-Multanowski M, Madetko-Talowska A, Günther CC, Jagła M, Tomasik T and Saugstad OD: Gene expression profiling in preterm infants: New aspects of bronchopulmonary dysplasia development. PLoS One 8: e78585, 2013

3. Warburton D, Bellusci S, De Langhe S, Del Moral PM, Fleury V, Mailleux A, Tefft D, Unbekandt M, Wang K and Shi W: Molecular mechanisms of early lung specification and branching morphogenesis. Pediatr Res 57: R26-R37, 2005.

4. Thébaud B: Angiogenesis in lung development, injury and repair: Implications for chronic lung disease of prematurity. Neonatology 91: 291-297, 2007.

5. Rojas M, Xu J, Woods CR, Mora AL, Spears W, Roman J and Brigham KL: Bone marrow-derived mesenchymal stem cells in repair of the injured lung. Am J Respir Cell Mol Biol 33: 145-152, 2005.

6. Yam J, Frank L and Roberts RJ: Oxygen toxicity: Comparison of lung biochemical responses in neonatal and adult rats. Pediatr Res 12: 115-119, 1978.

7. Mei SH, McCarter SD, Deng Y, Parker CH, Liles WC and Stewart DJ: Prevention of LPS-induced acute lung injury in mice by mesenchymal stem cells overexpressing angiopoietin 1. PLoS Med 4: e269, 2007.

8. Ortiz LA, Gambelli F, McBride C, Gaupp D, Baddoo M, Kaminski $\mathrm{N}$ and Phinney DG: Mesenchymal stem cell engraftment in lung is enhanced in response to bleomycin exposure and ameliorates its fibrotic effects. Proc Natl Acad Sci USA 100: 8407-8411, 2003.

9. Xu J, Woods CR, Mora AL, Joodi R, Brigham KL, Iyer S and Rojas M: Prevention of endotoxin-induced systemic response by bone marrow-derived mesenchymal stem cells in mice. Am J Physiol Lung Cell Mol Physiol 293: L131-L141, 2007.

10. Aslam M, Baveja R, Liang OD, Fernandez-Gonzalez A, Lee C, Mitsialis SA and Kourembanas S: Bone marrow stromal cells attenuate lung injury in a murine model of neonatal chronic lung disease. Am J Respir Crit Care Med 180: 1122-1130, 2009.

11. van Haaften T, Byrne R, Bonnet S, Rochefort GY, Akabutu J, Bouchentouf M, Rey-Parra GJ, Galipeau J, Haromy A, Eaton F, et al: Airway delivery of mesenchymal stem cells prevents arrested alveolar growth in neonatal lung injury in rats. Am J Respir Crit Care Med 180: 1131-1142, 2009.

12. Lee JW,Fang X,Krasnodembskaya A, Howard JP and Matthay MA: Concise review: Mesenchymal stem cells for acute lung injury: Role of paracrine soluble factors. Stem Cells 29: 913-919, 2011.

13. Iosef C, Alastalo TP, Hou Y, Chen C, Adams ES, Lyu SC, Cornfield DN and Alvira CM: Inhibiting NF- $\kappa \mathrm{B}$ in the developing lung disrupts angiogenesis and alveolarization. Am J Physiol Lung Cell Mol Physiol 302: L1023-L1036, 2012. 
14. Vicencio AG, Lee CG, Cho SJ, Eickelberg O, Chuu Y, Haddad GG and Elias JA: Conditional overexpression of bioactive transforming growth factor-betal in neonatal mouse lung: A new model for bronchopulmonary dysplasia? Am J Respir Cell Mol Biol 31: 650-656, 2004

15. Jelkmann W: Erythropoietin: Structure, control of production, and function. Physiol Rev 72: 449-489, 1992.

16. Lipsic E, Schoemaker RG, van der Meer P, Voors AA, van Veldhuisen DJ and van Gilst WH: Protective effects of erythropoietin in cardiac ischemia: From bench to bedside. J Am Coll Cardiol 48: 2161-2167, 2006.

17. King VR, Averill SA, Hewazy D, Priestley JV, Torup L and Michael-Titus AT: Erythropoietin and carbamylated erythropoietin are neuroprotective following spinal cord hemisection in the rat. Eur J Neurosci 26: 90-100, 2007.

18. Shang Y, Li X, Prasad PV, Xu S, Yao S, Liu D, Yuan S and Feng D: Erythropoietin attenuates lung injury in lipopolysaccharide treated rats. J Surg Res 155: 104-110, 2009.

19. Ozer EA, Kumral A, Ozer E, Yilmaz O, Duman N, Ozkal S, Koroglu T and Ozkan H: Effects of erythropoietin on hyperoxic lung injury in neonatal rats. Pediatr Res 58: 38-41, 2005.

20. Shang Y, Jiang YX, Xu SP, Wu Y, Wu ZY, Yuan SY and Yao SL: Reduction of pulmonary inflammatory response by erythropoietin in a rat model of endotoxaemia. Chin Med J (Engl) 122 834-838, 2009

21. Zhang H, Fang J, Su H, Yang M, Lai W, Mai Y and Wu Y: Bone marrow mesenchymal stem cells attenuate lung inflammation of hyperoxic newborn rats. Pediatr Transplant 16: 589-599, 2012.

22. Okabe M, Ikawa M, Kominami K, Nakanishi T and Nishimune $Y$ 'Green mice' as a source of ubiquitous green cells. FEBS Lett 407: 313-319, 1997.

23. Han X, Zhao L, Lu G, Ge J, Zhao Y, Zu S, Yuan M, Liu Y, Kong F, Xiao Z and Zhao S: Improving outcomes of acute kidney injury using mouse renal progenitor cells alone or in combination with erythropoietin or suramin. Stem Cell Res Ther 4: 74, 2013.

24. Balasubramaniam V, Mervis CF, Maxey AM, Markham NE and Abman SH: Hyperoxia reduces bone marrow, circulating, and lung endothelial progenitor cells in the developing lung: Implications for the pathogenesis of bronchopulmonary dysplasia. Am J Physiol Lung Cell Mol Physiol 292: L1073-L1084, 2007.

25. Kunig AM, Balasubramaniam V, Markham NE, Seedorf G Gien J and Abman SH: Recombinant human VEGF treatment transiently increases lung edema but enhances lung structure after neonatal hyperoxia. Am J Physiol Lung Cell Mol Physiol 291: L1068-L1078, 2006.

26. Yang H, Xie Z, Wei L, Yang H, Yang S, Zhu Z, Wang P, Zhao C and Bi J: Human umbilical cord mesenchymal stem cell-derived neuron-like cells rescue memory deficits and reduce amyloid-beta deposition in an A $\beta P P / P S 1$ transgenic mouse model. Stem Cell Res Ther 4: 76, 2013.

27. Zhang H, Fang J, Wu Y, Mai Y, Lai W and Su H: Mesenchymal stem cells protect against neonatal rat hyperoxic lung injury. Expert Opin Biol Ther 13: 817-829, 2013.

28. Tropea KA, Leder E, Aslam M, Lau AN, Raiser DM, Lee JH, Balasubramaniam V, Fredenburgh LE, Alex Mitsialis S, Kourembanas S and Kim CF. Bronchioalveolar stem cells increase after mesenchymal stromal cell treatment in a mouse model of bronchopulmonary dysplasia. Am J Physiol Lung Cell Mol Physiol 302: L829-L837, 2012.

29. Abman SH and Matthay MA: Mesenchymal stem cells for the prevention of bronchopulmonary dysplasia: Delivering the secretome. Am J Respir Crit Care Med 180: 1039-1041, 2009.
30. Hennrick KT, Keeton AG, Nanua S, Kijek TG, Goldsmith AM, Sajjam US, Bentley JK, Lama VN, Moore BB, Schumacher RE, et al: Lung cells from neonates show a mesenchymal stem cell phenotype. Am J Respir Crit Care Med 175: 1158-1164, 2007.

31. Jiang Y, Jahagirdar BN, Reinhardt RL, Schwartz RE, Keene CD, Ortiz-Gonzalez XR, Reyes M, Lenvik T, Lund T, Blackstad M, et al: Pluripotency of mesenchymal stem cells derived from adult marrow. Nature 418: 41-49, 2002.

32. Krause DS, Theise ND, Collector MI, Henegariu O, Hwang S, Gardner R, Neutzel S and Sharkis SJ: Multi-organ, multi-lineage engraftment by a single bone marrow-derived stem cell. Cell 105: 369-377, 2001.

33. Wen ST, Chen W, Chen HL, Lai CW, Yen CC, Lee KH, Wu SC and Chen CM: Amniotic fluid stem cells from EGFP transgenic mice attenuate hyperoxia-induced acute lung injury. PLoS One 8: e75383, 2013

34. Gore AV, Bible LE, Livingston DH, Mohr AM and Sifri ZC. Mesenchymal stem cells enhance lung recovery after injury, shock, and chronic stress. Surgery 159:1430-1435, 2016.

35. Mitsialis SA and Kourembanas S. Stem cell-based therapies for the newborn lung and brain: Possibilities and challenges. Semin Perinatol 40: 138-151, 2016

36. Luan Y, Zhang X, Kong F, Cheng GH, Qi TG and Zhang ZH: Mesenchymal stem cell prevention of vascular remodeling in high flow-induced pulmonary hypertension through a paracrine mechanism. Int Immunopharmacol 14: 432-437, 2012.

37. Buckley S and Warburton D: Dynamics of metalloproteinase-2 and -9 , TGF-beta, and uPA activities during normoxic vs. hyperoxic alveolarization. Am J Physiol Lung Cell Mol Physiol 283: L747-L754, 2002.

38. Ekekezie II, Thibeault DW, Simon SD, Norberg M, Merrill JD, Ballard RA, Ballard PL and Truog WE: Low levels of tissue inhibitors of metalloproteinases with a high matrix metalloproteinase-9/tissue inhibitor of metalloproteinase-1 ratio are present in tracheal aspirate fluids of infants who develop chronic lung disease. Pediatrics 113: 1709-1714, 2004.

39. Harijith A, Choo-Wing R, Cataltepe S, Yasumatsu R, Aghai ZH, Janér J, Andersson S, Homer RJ and Bhandari V: A role for matrix metalloproteinase 9 in IFN $\gamma$-mediated injury in developing lungs: Relevance to bronchopulmonary dysplasia. Am J Respir Cell Mol Biol 44: 621-630, 2011.

40. Abman SH: Impaired vascular endothelial growth factor signaling in the pathogenesis of neonatal pulmonary vascular disease. Adv Exp Med Biol 661: 323-335, 2010.

41. De Paepe ME, Mao Q, Powell J, Rubin SE, DeKoninck P, Appel N, Dixon M and Gundogan F: Growth of pulmonary microvasculature in ventilated preterm infants. Am J Respir Crit Care Med 173: 204-211, 2006.

42. Maniscalco WM, Watkins RH, Pryhuber GS, Bhatt A, Shea C and Huyck H: Angiogenic factors and alveolar vasculature: Development and alterations by injury in very premature baboons. Am J Physiol Lung Cell Mol Physiol 282: L811-L823, 2002.

43. Hosford GE and Olson DM: Effects of hyperoxia on VEGF, its receptors and HIF-2 in the newborn rat lung. Am J Physiol Lung Cell Mol Physiol 285: L161-L168, 2003.

44. Acarregui MJ, Penisten ST, Goss KL, Ramirez K and Snyder JM: Vascular endothelial growth factor gene expression in human fetal lung in vitro. Am J Respir Cell Mol Biol 20: 14-23, 1999.

45. Le Cras TD, Markham NE, Tuder RM, Voelkel NF and Abman SH: Treatment of newborn rats with a VEGF receptor inhibitor causes pulmonary hypertension and abnormal lung structure. Am J Physiol Lung Cell Mol Physiol 283: L555-L562, 2002. 